\title{
Article \\ Stability of Domoic Acid in 50\% Methanol Extracts and Raw Fecal Material from Bowhead Whales (Balaena mysticetus)
}

\author{
Emily K. Bowers ${ }^{1}$, Raphaela Stimmelmayr ${ }^{2}$ and Kathi A. Lefebvre ${ }^{1, * \mathbb{D}}$ \\ 1 Northwest Fisheries Science Center, Environmental and Fisheries Sciences Division, National Marine \\ Fisheries Service, NOAA, 2725 Montlake Blvd E, Seattle, WA 98112, USA; emily.bowers@noaa.gov \\ 2 The North Slope Borough Department of Wildlife Management, P.O. Box 69, Utqiagvik, AK 99723, USA; \\ rafstimmel@gmail.com \\ * Correspondence: kathi.lefebvre@noaa.gov
}

check for updates

Citation: Bowers, E.K.; Stimmelmayr, R.; Lefebvre, K.A. Stability of Domoic Acid in 50\% Methanol Extracts and Raw Fecal Material from Bowhead Whales (Balaena mysticetus). Mar. Drugs 2021, 19, 423. https:// doi.org/10.3390/md19080423

Academic Editor: Pedro Reis Costa

Received: 9 June 2021

Accepted: 23 July 2021

Published: 27 July 2021

Publisher's Note: MDPI stays neutral with regard to jurisdictional claims in published maps and institutional affiliations.

Copyright: (c) 2021 by the authors. Licensee MDPI, Basel, Switzerland. This article is an open access article distributed under the terms and conditions of the Creative Commons Attribution (CC BY) license (https:/ / creativecommons.org/licenses/by/ $4.0 /)$.

\begin{abstract}
Domoic acid (DA), the toxin causing amnesic shellfish poisoning (ASP), is produced globally by some diatoms in the genus Pseudo-nitzschia. DA has been detected in several marine mammal species in the Alaskan Arctic, raising health concerns for marine mammals and subsistence communities dependent upon them. Gastrointestinal matrices are routinely used to detect Harmful Algal Bloom (HAB) toxin presence in marine mammals, yet DA stability has only been studied extensively in shellfish-related matrices. To address this knowledge gap, we quantified DA in bowhead whale fecal samples at multiple time points for two groups: (1) $50 \%$ methanol extracts from feces, and (2) raw feces stored in several conditions. DA concentrations decreased to $70 \pm 7.1 \%$ of time zero $\left(\mathrm{T}_{0}\right)$ in the $50 \%$ methanol extracts after 2 weeks, but remained steady until the final time point at 5 weeks $\left(66 \pm 5.7 \% \mathrm{~T}_{0}\right)$. In contrast, DA concentrations were stable or increased in raw fecal material after 8 weeks of freezer storage $\left(-20^{\circ} \mathrm{C}\right)$, at room temperature (RT) in the dark, or refrigerated at $1{ }^{\circ} \mathrm{C}$. DA concentrations in raw feces stored in an incubator $\left(37^{\circ} \mathrm{C}\right)$ or at RT in the light decreased to $77 \pm 2.8 \%$ and $90 \pm 15.0 \% \mathrm{~T}_{0}$ at 8 weeks, respectively. Evaporation during storage of raw fecal material is a likely cause of the increased DA concentrations observed over time with the highest increase to $126 \pm 7.6 \% \mathrm{~T}_{0}$ after 3.2 years of frozen storage. These results provide valuable information for developing appropriate sample storage procedures for marine mammal fecal samples.
\end{abstract}

Keywords: marine mammals; toxin degradation; harmful algal bloom toxins; storage conditions; ELISA; domoic acid

\section{Introduction}

Harmful algal blooms (HABs) create health concerns for humans and wildlife worldwide due to the production of potent toxins that can accumulate in filter-feeding organisms such as planktivorous fish, bivalves, krill, and other invertebrates [1-5]. These organisms act as vectors of HAB toxins to upper trophic level predators and can cause significant health impacts and mortality in fish, marine mammals, and seabirds [6-12]. HAB toxin risks to human seafood consumers have been mitigated by the implementation of seafood safety regulatory limits for allowable levels of toxins in seafood designated for human consumption [13]. There are growing concerns, however, regarding the apparent increase in $\mathrm{HAB}$ frequency, toxicity, and geographic and temporal distribution around the world, to which climate change, eutrophication, and ballast water transfer are contributing $[3,14,15]$. Changes in $\mathrm{HAB}$ distribution raise public health and wildlife management concerns, particularly for locations previously unexposed or poorly monitored for HABs, such as the expansive coastlines of Alaska [16,17].

Domoic acid (DA) is a common HAB toxin, produced by some diatoms in the genus Pseudo-nitzschia [18]. Acute exposure to DA causes the human neurological illness amnesic shellfish poisoning (ASP) [19]. Most commonly contracted by consuming shellfish that 
feed on toxic phytoplankton, ASP can be fatal with high levels of DA ingestion [9]. In marine mammals such as California sea lions (Zalophus californianus) and Northern fur seals (Callorhinus ursinus), DA causes symptoms such as seizures, ataxia, reduced responsiveness, and brain and heart lesions [20,21]. DA toxicosis can result in mortality, as was the case in the 1998 unusual mortality event (UME) of California sea lions along the central California coast $[7,10]$. Even sublethal exposure is cause for concern, as DA has been found to cause chronic neurological effects such as memory and learning impairment in sea lions $(Z$. californianus) [22]. Exposure to DA has been reported in humpback (Megaptera novaeangliae), blue (Balaenoptera musculus), minke (B. acutorostrata), pygmy (Kogia breviceps), dwarf sperm (K. sima), and North Atlantic right whales (Eubalaena glacialis) [5,23-25], Northern fur seals (Callorhinus ursinus) [21], harbor seals (Phoca vitulina) [26,27], Northern sea otters (Enhydra lutris) [28], and 13 Arctic marine mammal species including Pacific walruses (Odobenus rosmarus), bowhead whales (Balaena mysticetus), and ice seals (Pusa hispida, Histriophoca fasciata, Erignathus barbatus, Phoca largha) [17].

Marine mammals are important subsistence resources for Arctic and subarctic communities. Therefore, monitoring the impact of HAB toxins on Arctic marine mammal health is of critical importance for many local, state, federal, academic, and tribal institutions, nationally and internationally, that participate in research on Arctic wildlife and ecosystem health. Gastrointestinal (GI) contents have been the primary matrices in which HAB toxins are quantified for routine marine mammal monitoring and health assessments during UMEs; therefore, validating the reliability of quantifications from these matrices is of great importance [17].

Many studies have been conducted assessing the chemical and biological stability of DA in experimental settings and in matrices associated with seafood safety. We know that DA is stable at room temperature in saline solution [29], and that it degrades with sunlight exposure in seawater $[30,31]$ and when stored at high temperatures and extreme $\mathrm{pH}$ in aqueous solution $[32,33]$. DA depurates in the bodies of living vector organisms at various rates, depending on the species [19], but is not degraded via steaming or autoclaving in harvested shellfish [34] and was even reported to become more concentrated in scallops stored at $12{ }^{\circ} \mathrm{C}$ [35]. However, little is known about the stability of DA in routinely-used marine mammal matrices such as GI contents. Toxin stability between sample collection and quantification is paramount, as it underpins all upstream analyses and results interpretation. Delayed sample collection and improper or prolonged storage are not uncommon for remote field sampling, making it imperative to quantify potential impacts of these factors on the accuracy of toxin measurements in GI contents from harvested, stranded, or dead marine mammals sampled in the field.

This study aims to characterize DA (Figure 1) stability in field-collected marine mammal feces and fecal extracts under various storage conditions. DA concentration in bowhead whale (Balaena mysticetus) feces was quantified at multiple timepoints for two groups: (1) $50 \%$ methanol extracts from feces (Extract group; stored at $1{ }^{\circ} \mathrm{C}$ in the refrigerator) and (2) raw feces (Raw Feces Treatment groups; stored at $-20^{\circ} \mathrm{C}$ in the freezer, $1{ }^{\circ} \mathrm{C}$ in the refrigerator, room temperature (RT) dark, RT light, or in an incubator at $37^{\circ} \mathrm{C}$ ). Toxin stability, as percent of initial concentration $\left(\% \mathrm{~T}_{0}\right)$, is reported here for each study group. 


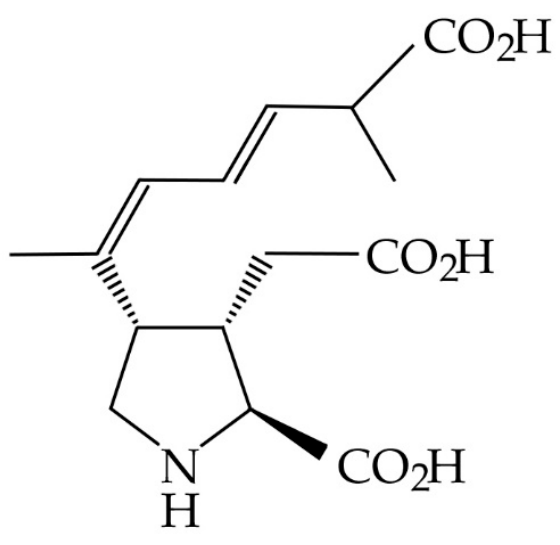

Figure 1. The chemical structure of domoic acid.

\section{Results \& Discussion}

\subsection{Extract Group}

We extracted bowhead whale feces collected from five individual whales using $50 \%$ methanol, and extracts from each replicate were repeatedly analyzed via enzyme-linked immunosorbent assay (ELISA) over 5 weeks (see the Supplementary Materials). Extracts were refrigerated in the dark at $1{ }^{\circ} \mathrm{C}$ for the duration of the study. The average DA concentration (as $\% \mathrm{~T}_{0}$ ) declined to $87 \pm 4.1 \%$ after 1 week, then to $70 \pm 7.1 \%$ after 2 weeks (Figure 2). The $\% \mathrm{~T}_{0}$ does not appear to decline at the same rate after 2 weeks: the 5 -week $\mathrm{T}_{0}(66 \pm 5.7 \%)$ is comparable to the $\mathrm{T}_{0}$ after 2 weeks, with the $\% \mathrm{~T}_{0}$ at week 3 being slightly higher $(85 \pm 4.1 \%)$. The standard errors of the mean (SEMs) were relatively low at all time points $(\leq 7.1 \%$; Figure 2$)$. While stability of fecal methanol extracts has not been reported to date apart from this study, degradation of shellfish methanol extracts over time has been reported or suggested in several other studies, to varying degrees [32,35-37]. Variability between reported trends (e.g., short-term, dramatic degradation in Smith et al. [35] versus slow degradation over months in Vale and Sampayo [37] versus the moderate degradation observed here) may be attributable to differences in methanol percentage, methanol-tosample ratio, or sample matrix. Collectively, our Extract group results suggest that DA from marine mammal feces extracted in $50 \%$ methanol is subject to moderate degradation $(\sim 30 \%)$ in at least the first 2 weeks of refrigeration. To obtain the most accurate results, we recommend analyzing extracts as soon as possible (within 1 week of extraction).

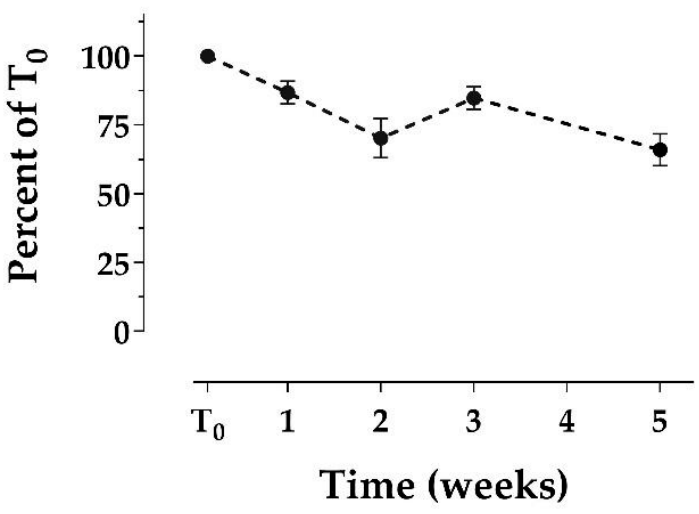

Figure 2. Stability of domoic acid in 50\% methanol extracts from bowhead whale feces over time, reported as the average of the percent of time-zero concentration. Extracts were refrigerated at $1{ }^{\circ} \mathrm{C}$ in the dark. Each time point consists of the same $n=5$ samples. Error bars display the standard error of the mean (SEM). Domoic acid concentrations ranged from $57 \mathrm{ng} / \mathrm{g}$ to $1161 \mathrm{ng} / \mathrm{g}$, which were well above the minimum detection limit of $4 \mathrm{ng} / \mathrm{g}$. 


\subsection{Treatment Group}

Replicates of $n=4$ bowhead whale fecal samples collected from four individual whales were stored in five treatments: (1) freezer $\left(-20^{\circ} \mathrm{C}\right),(2)$ refrigerator $\left(1^{\circ} \mathrm{C}\right),(3)$ room temperature (RT) in the dark, (4) RT in the light, and (5) in an incubator $\left(\sim 37^{\circ} \mathrm{C}\right)$. Sample aliquots were analyzed repeatedly to quantify DA concentrations via ELISA over 8 weeks. Additionally, we opportunistically analyzed $n=4$ samples that were stored frozen for 3.2 and 3.8 years (long-term frozen). DA concentrations appeared reasonably consistent over time in 0-8-week (short-term) treatments (Figure 3), while the long-term frozen samples yielded consistent but slightly higher concentrations (Figure 4).

Freezer

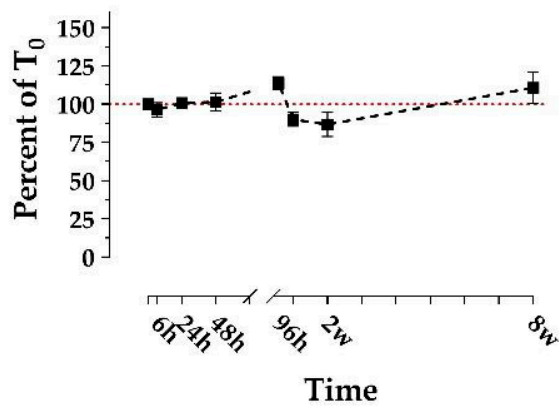

Refrigerator

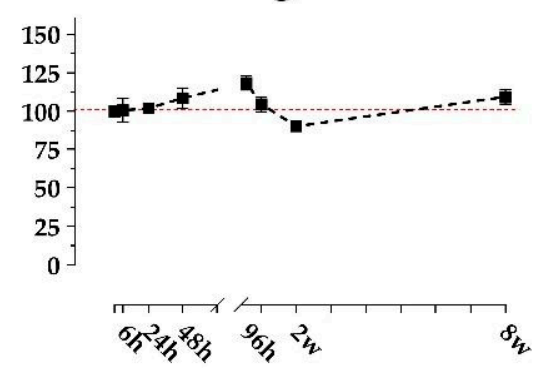

\section{RT Light}

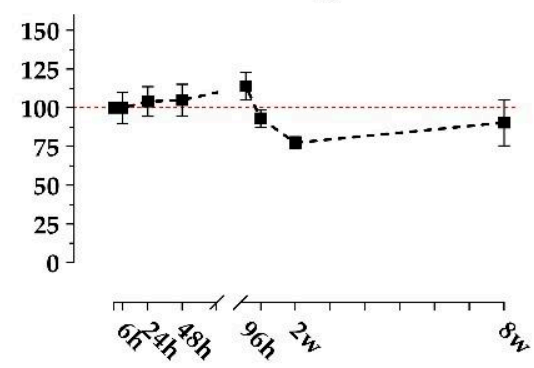

\section{RT Dark}

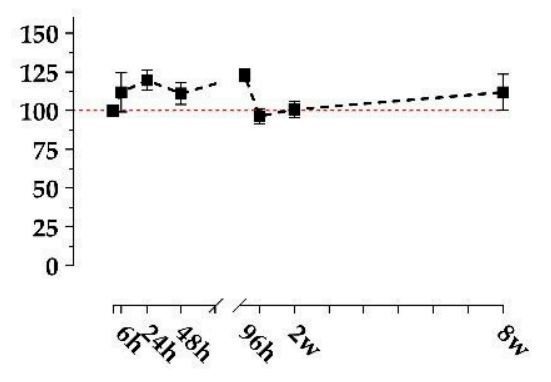

Warm

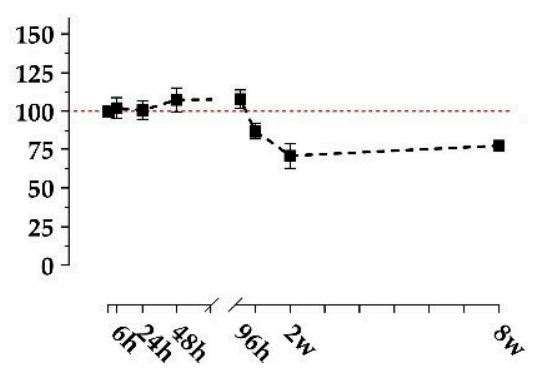

Figure 3. Stability of domoic acid in raw bowhead whale feces over time, reported as the average of the percent of time-zero concentration. Fecal aliquots were stored in 5 treatment conditions (freezer at $-20^{\circ} \mathrm{C}$, refrigerator at $1{ }^{\circ} \mathrm{C}$, room temperature (RT) dark, RT light, and incubator at $37^{\circ} \mathrm{C}$ ). Each time point consists of $n=4$ samples. A $100 \%$ reference line is included in red. Error bars display the SEM. Domoic acid concentrations ranged from $67 \mathrm{ng} / \mathrm{g}$ to $9812 \mathrm{ng} / \mathrm{g}$, which were well above the minimum detection limit of $4 \mathrm{ng} / \mathrm{g}$. 


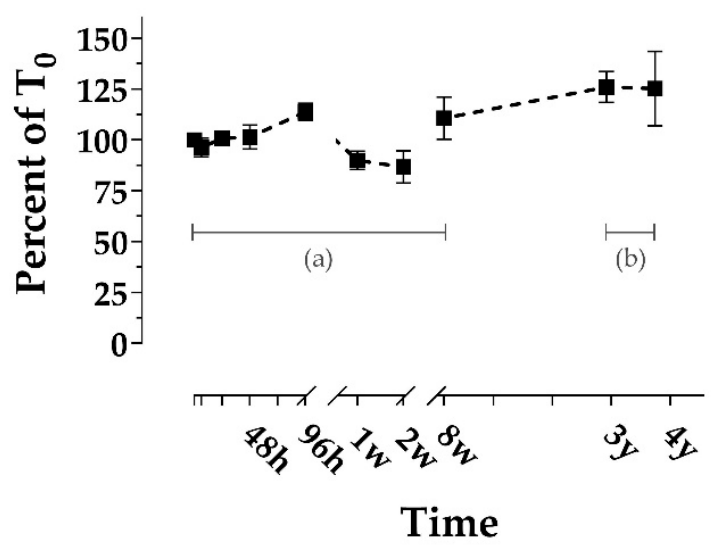

Figure 4. Stability of domoic acid in raw, frozen bowhead whale feces over time, reported as the average of the percent of time-zero concentration. Short-term time points (a) consist of the same $n=4$ samples repeatedly analyzed (see Figure 1 ). Long-term time points (b) consist of separate $n=4$ samples analyzed at 2 time points (3.2 and 3.8 years). Error bars display the SEM. Domoic acid concentrations ranged from $124 \mathrm{ng} / \mathrm{g}$ to $9812 \mathrm{ng} / \mathrm{g}$, which were well above the minimum detection limit of $4 \mathrm{ng} / \mathrm{g}$.

Average DA concentration (as $\% \mathrm{~T}_{0}$ ) remained between approximately 70 and $110 \%$ in all short-term treatments (Figure 3), while long-term frozen $\% \mathrm{~T}_{0}$ increased to $126 \pm 7.6 \%$ and $125 \pm 18.3 \%$ for the 3.2 and 3.8-year time points, respectively (Figure 4). The rise above $100 \% \mathrm{~T}_{0}$ in long-term frozen samples is likely attributable to moisture evaporation from within the sample, causing DA to concentrate. Smith et al. [35] also reported increased DA concentration in raw scallops stored at $12{ }^{\circ} \mathrm{C}$ for $\leq 3$ days, likewise implicating evaporation. Additionally, the long-term increases could be due at least in part to variability between ELISA kits and days. While the RT Light and Warm samples appeared to decline relatively rapidly between $96 \mathrm{~h}$ and 2 weeks, this observation is not sufficiently distinct to draw qualitative conclusions (Figure 3). However, across the Freezer, Refrigerator, and RT Dark treatments, we did notice slight increases at the 96-h mark, as well as a slight increase at the 8-week mark in the Freezer and Refrigerator treatments (Figure 3). This implicates an artifact introduced by the ELISA plates or the standards with which time points are analyzed. The SEM was relatively low for all short-term time points and treatments but higher for the 3.8-year frozen time point (Figure 4). The higher 3.8-year SEM is likely attributed to moisture evaporation occurring to varying degrees over time between replicates.

Altogether, we observe no empirically obvious reductions in DA concentration in any treatment. This suggests that DA is robust against degradation in marine mammal feces in a surprising variety of conditions, and that concerns of significantly underestimated values need not necessarily be raised based on sample storage conditions of $\leq 8$ weeks. The moderate increases observed in long-term frozen concentrations ( $25 \%$ above $\left.\mathrm{T}_{0}\right)$ were well within an order of magnitude of $\mathrm{T}_{0}$. However, care should be taken to minimize sample evaporation and analyze samples promptly whenever possible to yield the most accurate results. Inflating DA concentrations by $25 \%$ may be a reasonable adjustment for samples from which evaporation is suspected.

\section{Materials \& Methods}

\subsection{Sample Collection and Selection}

During 2016-2019, fecal samples from subsistence-harvested bowhead whales were collected in Utqiagvik, Alaska. Sections of colon were cut and fecal matter was removed using plastic spoons. Fecal samples were collected in 50-mL polypropylene screw-cap tubes (Falcon-BD, Franklin Lakes, NJ, USA) and stored frozen at $-20{ }^{\circ} \mathrm{C}$ until time of analysis. Samples were shipped to the Northwest Fisheries Science Center's Wildlife AlgalToxin Research and Response Network (WARRN-West) laboratory (Seattle, WA, USA) for toxin analysis. 
All samples were originally subsampled and analyzed for DA 2-8 months after sample collection. Remaining unanalyzed sample material was kept frozen. We selected samples for the present study based on their original DA concentration and date of analysis, choosing samples with original concentrations of $>100 \mathrm{ng} / \mathrm{g}$ whenever possible.

\subsection{Study Setup}

The goal of the Extract group was to characterize DA stability in 50\% methanol extracts from marine mammal feces stored in the cold and dark. We extracted raw bowhead whale feces $(n=5)$ following the extraction procedure outlined for the Extract group below (3.3.1). Extracts were stored in a Kenmore top-mount refrigerator (model no. 253.68972802).

The goal of the Treatment group was to characterize DA stability over time in raw marine mammal feces under various relevant conditions. Fecal aliquots from $n=4$ bowhead whales were stored under 5 treatments: freezer, refrigerator, room temperature (RT) dark, RT light, and warm incubator (Table 1).

Table 1. Summary of Treatment group design and justification.

\begin{tabular}{|c|c|c|}
\hline Treatment Name & Temperature & Justification \\
\hline Freezer & $-20^{\circ} \mathrm{C}$ & $\begin{array}{l}\text { Ideal condition in which samples are } \\
\text { stored immediately upon collection }\end{array}$ \\
\hline Refrigerator & $1^{\circ} \mathrm{C}$ & $\begin{array}{l}\text { Second best storage option if freezing is } \\
\text { not possible }\end{array}$ \\
\hline $\begin{array}{l}\text { Room Temperature } \\
\text { (RT)-Dark }\end{array}$ & $18{ }^{\circ} \mathrm{C} \pm 2{ }^{\circ} \mathrm{C}^{1}$ & $\begin{array}{l}\text { Accidental/unavoidable exposure to } \\
\text { ambient temperatures (e.g., field, } \\
\text { laboratory) in the dark }\end{array}$ \\
\hline $\begin{array}{l}\text { Room Temperature } \\
\text { (RT)_Light }\end{array}$ & $18{ }^{\circ} \mathrm{C} \pm 2{ }^{\circ} \mathrm{C}^{1}$ & $\begin{array}{l}\text { Accidental/unavoidable exposure to } \\
\text { ambient temperatures (e.g., field, } \\
\text { laboratory) in daylight }\end{array}$ \\
\hline Warm & $35^{\circ} \mathrm{C} \pm 3^{\circ} \mathrm{C}^{1}$ & $\begin{array}{l}\text { Delay of sample collection from a } \\
\text { dead carcass }\end{array}$ \\
\hline
\end{tabular}

${ }^{1}$ Mean temperature \pm standard deviation.

During the treatment period, freezer samples were stored in a Frigidaire freezer (model FFFU21M1QWE), and refrigerator samples were stored in the refrigerator specified above. All RT samples were kept on a North-facing window sill, and RT light samples received natural (but not direct) sunlight during daylight hours in Seattle, WA, USA (December-February). RT light aliquot tubes were lined up on wire racks that allowed full light exposure, while RT dark samples were kept under a light-proof box. Ambient temperature was monitored for the RT samples using a TP-50 digital air thermometer (ThermoPro, Toronto, ON, Canada). Warm samples were kept in a Lab-Line (model no. 120) incubator, and internal incubator temperature was monitored using a Fisher USA thermometer ( $90 \mathrm{~mm}$, Waltham, MA USA).

Additional raw fecal samples were also analyzed after two durations of freezer storage (up to 3.8 years) to assess long-term DA stability under standard storage conditions $\left(-20^{\circ} \mathrm{C}\right.$; see freezer specifications above). Along with the four samples used in the 8-week shortterm treatment study described above, we analyzed four additional fecal samples at two time points each (3.2 and 3.8 years of frozen storage).

\subsection{Toxin Extraction}

\subsubsection{Extract Group}

We extracted DA via methanol dilution, homogenization, and centrifugation. Raw fecal samples were thawed at room temperature and stirred thoroughly. For each sample, we weighed out approximately $1 \mathrm{~g}$ of fecal material (Scout STX balance, Ohaus, Parsippany, $\mathrm{NJ}, \mathrm{USA}$ ) and aliquoted it into a 14-mL polypropylene pop-cap tube (Falcon-BD, Franklin Lakes, NJ, USA). We added 50\% methanol (the standard extraction solvent for DA ELISA analyses) to each aliquot at $3 \times$ the aliquot weight for a 1-in-4 dilution. Sample solutions 
were briefly vortexed on high (Analogue Vortex Mixer, sn 060223013, VWR, Radnor, PA, USA), then homogenized with a generator probe (GLH 850, Omni-International, Kennesaw, GA, USA) for $1 \mathrm{~min}$ at $2100 \mathrm{rpm}$. Homogenized samples were then centrifuged at $5000 \mathrm{rpm}$ for $20 \mathrm{~min}$ at $4{ }^{\circ} \mathrm{C}$ (CR3i centrifuge, Jouan, Milford, MA, USA). Supernatants (the extracts) were poured into 4-mL glass amber vials (National C4015-2W Thermo Scientific, Waltham, MA USA) and refrigerated until further analysis. Directly prior to toxin quantification, we filtered $200 \mu \mathrm{g}$ subsamples of the extracts for analysis (Ultra-Free Centrifugal filters, $0.22 \mu \mathrm{m}$, UFC30GVNB, Millipore Sigma, Chicago, IL, USA). Extracts were sampled, filtered, and re-analyzed at each time point.

\subsubsection{Treatment Group}

Toxin extraction for the raw, short-term Treatment samples is modified from the Extract group extraction described above. Samples were thawed in a refrigerator for $4 \mathrm{~h}$, stirred, and aliquoted. From each sample, we weighed out five 3-g aliquots (one per treatment) and stored them in 14-mL tubes. We extracted a base time point $\left(T_{0}\right)$ from each aliquot directly prior to beginning treatments. At each time point, the aliquots in 14-mL tubes were again stirred (except the frozen treatment aliquots). We then aliquoted $0.25 \mathrm{~g}$ of feces from each 14-mL tube into 1.5-mL plastic microfuge tubes on ice (frozen treatment aliquots were scraped from the top of the still-frozen samples). Light exposure was minimized for all treatment groups during aliquoting except for the RT light treatment. After aliquoting, we added $50 \%$ methanol to the $1.5-\mathrm{mL}$ microfuge tubes as described above. Fecal-methanol solutions were vortexed on high for three 30-s increments (90 s total; see above vortexer information), being held in the refrigerator for approximately $2 \mathrm{~min}$ between increments to keep cool. After $90 \mathrm{~s}$ of vortexing, samples with remaining fecal clumps were vortexed for additional time and/or clumps were broken using metal spatulas until samples were of uniform consistency. Finally, we incubated the fecal-methanol slurries in the freezer for $5 \mathrm{~min}$, then centrifuged them (accuSpin Micro 17 Fisher Scientific, Waltham, MA USA) for $12 \mathrm{~min}$ at 12,000 rpm. Supernatant extracts were then poured off into clear 1.5-mL cryovials (220-3902-080, Evergreen Scientific, Caplugs CA, USA) and refrigerated until further analysis (mean 2.5 days). Directly prior to toxin quantification, extracts were filtered as described above. Aliquoting from 14-mL tubes and extraction was repeated at each time point; extracts were not re-analyzed. Long-term frozen treatment samples were aliquoted and extracted according to the procedure outlined for the Extract group (3.3.1), except long-term frozen samples were re-aliquoted and extracted at each time point (each extract was analyzed only once).

\subsection{Toxin Quantification}

We quantified DA via direct-competition ELISA using commercially-available Biosense ${ }^{\circledR}$ ASP ELISA kits (Biosense ${ }^{\circledR}$ Laboratories, Bergen, Norway). While these kits are intended for analyzing shellfish and water samples, previous studies by our team were performed to determine appropriate dilutions to avoid matrix effects from marine mammal matrices, and for for validation of other analytical methods compared to ELISA results [21,38]. Kits were used according to their manufacturer protocol with dilution modifications from Frame and Lefebvre [38] (base dilution of 1:100 sample: 50\% methanol, plus any additional dilution necessary to ensure each concentration falls within the kit's working range. Final dilutions were determined individually upon original analysis prior to this present study and remained constant throughout the study). Kit plates loaded with samples, standards, and reagents were incubated at room temperature on an orbital shaker (Bellco Biotechnology, Vineland, NJ, USA) for $75 \mathrm{~min}$, then washed (ELx50, sn 257474, BioTek, Winooski, VT, USA). Kit-provided color solution was added to all wells before plates were incubated again for $15 \mathrm{~min}$ on the orbital shaker. Well absorbance was quantified using a BioTek Epoch (sn 257814). The detection limit for fecal samples by ELISA was $4 \mathrm{ng} / \mathrm{g}$. Domoic acid concentrations quantified in all samples used in this study ranged from $57 \mathrm{ng} / \mathrm{g}$ to $9812 \mathrm{ng} / \mathrm{g}$. 


\subsection{Data Analysis}

We interpolated unknown DA concentrations using known standard absorbances and concentrations with the 4-parameter logistic curve fit model recommended in the Biosense ${ }^{\circledR}$ protocols. Resulting concentrations were reported as percentages of the respective initial concentrations, $T_{0}\left(\left[T_{i} / T_{0}\right] \times 100\right)$. For the Extract and short-term Treatment groups, we defined $\mathrm{T}_{0}$ as the DA concentration quantified at the beginning of the present study, controlling for any changes that may have occurred after original analyses in the past and the present study. Conversely, the purpose of the long-term frozen samples was to assess DA stability in the years following original sample analysis; hence, $\mathrm{T}_{0}$ for long-term frozen samples was defined as the original concentration quantified years prior.

No statistical analyses were used to evaluate this present study due to small sample sizes ( $n \leq 5$ replicates) which limited the reliability of data normality assessments and any subsequent parametric or non-parametric analyses [39-41]. Sample size was constrained in this study by sample availability, sample volume, and original toxin concentration.

\section{Conclusions}

This study aimed to characterize DA stability in extracted and raw marine mammal fecal material to assess the risk of toxin degradation due to storage time and conditions when quantifying DA in field-collected marine mammal GI samples for wildlife health assessments. This study provides evidence for DA being stable in raw bowhead whale feces frozen at $-20^{\circ} \mathrm{C}$ as well as stored in a refrigerator and at room temperature in the dark, with only slight toxin loss observed in the RT light treatment and moderate toxin loss in the $37^{\circ} \mathrm{C}$ incubator treatment with a storage period up to 8 weeks. Most notable are the findings that DA concentrations were not significantly reduced during longer term frozen storage up to 3.8 years, and in fact, that increases were observed, likely due to evaporative processes. DA appeared less stable over time in 50\% methanol extracts, decreasing to approximately $70 \%$ of $\mathrm{T}_{0}$ in the first two weeks and suggesting that $50 \%$ methanol extracts should be analyzed as promptly as possible. In addition to evaporative processes, inherent differences between plates and the execution of analyses may contribute to variability in toxin quantifications. However, the ELISA protocol calls for fresh standards to be prepared with each plate, thereby reducing any quantitative differences from plate and analyst performance between assays. Further studies are necessary to confirm the generalizability of these results; however, we expect results to be similar for other marine mammal species. Also, given that feces is one of the "messiest" marine mammal matrices, requiring a higher dilution than most marine mammal matrices to counter matrix effects [38], we anticipate other matrices will display similar (or greater) consistency in toxin concentration over time.

Supplementary Materials: The following are available online at https:/ / www.mdpi.com/article/10 $.3390 / \mathrm{md19080423/s1.}$

Author Contributions: Conceptualization, E.K.B., R.S. and K.A.L.; methodology, K.A.L. and E.K.B.; formal analysis, E.K.B.; investigation, E.K.B.; resources, R.S. and K.A.L.; data curation, E.K.B.; writing—original draft preparation, E.K.B.; writing—review and editing, E.K.B., R.S. and K.A.L.; visualization, E.K.B.; supervision, K.A.L.; project administration, K.A.L.; funding acquisition, K.A.L., R.S. All authors have read and agreed to the published version of the manuscript.

Funding: This research was funded through NOAA's National Centers for Coastal Ocean Science ECOHAB program (Grant \#NA20NOS4780195 to K.A.L.). This is ECOHAB contribution number ECO991.

Institutional Review Board Statement: Fecal sample collection occurred under NMFS research permit No. 21386 issued to the North Slope Borough Department of Wildlife Management (NSB DWM).

Data Availability Statement: The data presented in this study are available as Supplementary Material published with this manuscript.

Acknowledgments: We thank the whaling captains of Utqiagvik, Alaska and the Alaska Eskimo Whaling commission (AEWC) for allowing the sampling of their landed whales. We would also like 
to thank the many NSB DWM staff involved in the bowhead whale harvest monitoring program over the years for their help with sample collection. We thank Li-Jung Kuo, Irv Schultz, and Penny Swanson of NOAA's Northwest Fisheries Science Center for careful review of this manuscript.

Conflicts of Interest: The authors declare no conflict of interest.

\section{References}

1. Anderson, D.M.; Richlen, M.L.; Lefebvre, K.A. Harmful Algal Blooms in the Arctic. Available online: https:/ /arctic.noaa.gov / Report-Card/Report-Card-2018/ArtMID/7878/ArticleID/789/Harmful-Algal-Blooms-in-the-Arctic (accessed on 7 April 2020).

2. Bargu, S.; Powell, C.L.; Coale, S.L.; Busman, M.; Doucette, G.J.; Silver, M.W. Krill: A potential vector for domoic acid in marine food webs. Mar. Ecol. Prog. Ser. 2002, 237, 209-216. [CrossRef]

3. Hallegraeff, G.M. A review of harmful algal blooms and their apparent global increase. Phycologia 1993, 32, 79-99. [CrossRef]

4. Landsberg, J.H.; Lefebvre, K.A.; Flewelling, L.J. Effects of toxic microalgae on marine organisms. In Toxins and Biologically Active Compounds from Microalgae; Rossini, G.P., Ed.; CRC Press: Boca Raton, FL, USA, 2014; Volume 2, pp. $379-449$.

5. Lefebvre, K.A.; Bargu, S.; Kieckhefer, T.; Silver, M.W. From sanddabs to blue whales: The pervasiveness of domoic acid. Toxicon 2002, 40, 971-977. [CrossRef]

6. Bargu, S.; Lefebvre, K.; Silver, M.W. Effect of dissolved domoic acid on the grazing rate of krill Euphausia pacifica. Mar. Ecol. Prog. Ser. 2006, 312, 169-175. [CrossRef]

7. Lefebvre, K.A.; Powell, C.L.; Busman, M.; Doucette, G.J.; Moeller, P.D.; Silver, J.B.; Miller, P.E.; Hughes, M.P.; Singaram, S.; Silver, M.W.; et al. Detection of domoic acid in Northern anchovies and California sea lions associated with an unusual mortality event. Nat. Toxins 1999, 7, 85-92. [CrossRef]

8. Lefebvre, K.A.; Elder, N.E.; Hershberger, P.K.; Trainer, V.L.; Stehr, C.M.; Scholz, N.L. Dissolved saxitoxin causes transient inhibition of sensorimotor function in larval Pacific herring (Clupea harengus pallasi). Mar. Biol. 2005, 147, 1393-1402. [CrossRef]

9. Perl, T.M.; Bédard, L.; Kosatsky, T.; Hockin, J.C.; Todd, E.C.; Remis, R.S. An outbreak of toxic encephalopathy caused by eating mussels contaminated with domoic acid. N. Engl. J. Med. 1990, 322, 1775-1780. [CrossRef]

10. Scholin, C.A.; Gulland, F.; Doucette, G.J.; Benson, S.; Busman, M.; Chavez, F.P.; Cordaro, J.; DeLong, R.; De Vogelaere, A.; Harvey, J.; et al. Mortality of sea lions along the central California coast linked to a toxic diatom bloom. Nature 2000, 403, 80-84. [CrossRef] [PubMed]

11. White, A.W. Recurrence of kills of Atlantic herring (Clupea harengus harengus) caused by dinoflagellate toxins transferred through herbivorous zooplankton. Can. J. Fish. Aquat. Sci. 1980, 37, 2262-2265. [CrossRef]

12. Work, T.M.; Barr, B.; Beale, A.M.; Fritz, L.; Quilliam, M.A.; Wright, J.L.C. Epidemiology of domoic acid poisoning in brown pelicans (Pelecanus occidentalis) and Brandt's cormorants (Phalacrocorax penicillatus) in California. J. Zoo Wildl. Med. 1993, $24,54-62$.

13. Wekell, J.C.; Hurst, J.; Lefebvre, K. The origin of the regulatory limits for PSP and ASP toxins in shellfish. J. Shellfish Res. 2004, 23, 927-930.

14. Anderson, D.M. Red tides. Sci. Am. 1994, 271, 52-58. [CrossRef]

15. Van Dolah, F.M. Marine algal toxins: Origins, health effects, and their increased occurrence. Environ. Health Perspect. 2000, 108 (Suppl. S1), 133-141. [CrossRef] [PubMed]

16. Hallegraeff, G.M. Ocean climate change, phytoplankton community responses, and harmful algal blooms: A formidable predictive challenge. J. Phycol. 2010, 46, 220-235. [CrossRef]

17. Lefebvre, K.A.; Quakenbush, L.; Frame, E.; Huntington, K.B.; Sheffield, G.; Stimmelmayr, R.; Bryan, A.; Kendrick, P.; Ziel, H.; Goldstein, T.; et al. Prevalence of algal toxins in Alaskan marine mammals foraging in a changing Arctic and subarctic environment. Harmful Algae 2016, 55, 13-24. [CrossRef] [PubMed]

18. Bates, S. Ecophysiology and metabolism of ASP toxin production. NATO ASI Ser. G Ecol. Sci. 1998, 41, 405-426.

19. Lefebvre, K.A.; Robertson, A. Domoic acid and human exposure risks: A review. Toxicon 2010, 56, 218-230. [CrossRef]

20. Gulland, F.M.D.; Haulena, M.; Fauquier, D.; Langlois, G.; Lander, M.E.; Zabka, T.; Duerr, R. Domoic acid toxicity in Californian sea lions (Zalophus californianus): Clinical signs, treatment and survival. Vet. Rec. 2002, 150, 475-480. [CrossRef]

21. Lefebvre, K.A.; Robertson, A.; Frame, E.R.; Colegrove, K.M.; Nance, S.; Baugh, K.A.; Wiedenhoft, H.; Gulland, F.M.D. Clinical signs and histopathology associated with domoic acid poisoning in Northern fur seals (Callorhinus ursinus) and comparison of toxin detection methods. Harmful Algae 2010, 9, 374-383. [CrossRef]

22. Cook, P.F.; Reichmuth, C.; Rouse, A.A.; Libby, L.A.; Dennison, S.E.; Carmichael, O.T.; Kruse-Elliott, K.T.; Bloom, J.; Singh, B.; Fravel, V.A.; et al. Algal toxin impairs sea lion memory and hippocampal connectivity, with implications for strandings. Science 2015, 350, 1545-1547. [CrossRef]

23. Doucette, G.J.; Mikulski, C.M.; King, K.L.; Roth, P.B.; Wang, Z.; Leandro, L.F.; DeGrasse, S.L.; White, K.D.; De Biase, D.; Gillett, R.M.; et al. Endangered North Atlantic right whales (Eubalaena glacialis) experience repeated, concurrent exposure to multiple environmental neurotoxins produced by marine algae. Environ. Res. 2012, 112, 67-76. [CrossRef]

24. Fire, S.E.; Wang, Z.; Leighfield, T.A.; Morton, S.L.; McFee, W.E.; McLellan, W.A.; Litaker, R.W.; Tester, P.A.; Hohn, A.A.; Lovewell, G.; et al. Domoic acid exposure in pygmy and dwarf sperm whales (Kogia spp.) from Southeastern and mid-Atlantic U.S. waters. Harmful Algae 2009, 8, 658-664. [CrossRef] 
25. Fire, S.; Wang, Z.; Berman, M.; Langlois, G.; Morton, S.; Sekula-Wood, E.; Benitez-Nelson, C. Trophic transfer of the harmful algal toxin domoic acid as a cause of death in a minke whale (Balaenoptera acutorostrata) stranding in Southern California. Aquat. Mamm. 2010, 36, 342-350342. [CrossRef]

26. McHuron, E.A.; Greig, D.J.; Colegrove, K.M.; Fleetwood, M.; Spraker, T.R.; Gulland, F.M.D.; Harvey, J.T.; Lefebvre, K.A.; Frame, E.R. Domoic acid exposure and associated clinical signs and histopathology in Pacific harbor seals (Phoca vitulina richardii). Harmful Algae 2013, 23, 28-33. [CrossRef]

27. Hall, A.J.; Frame, E. Evidence of domoic acid exposure in harbour seals from Scotland: A potential factor in the decline in abundance? Harmful Algae 2010, 9, 489-493. [CrossRef]

28. Kreuder, C.; Miller, M.A.; Jessup, D.A.; Lowenstine, L.J.; Harris, M.D.; Ames, J.A.; Carpenter, T.E.; Conrad, P.A.; Mazet, J.A.K. Patterns of mortality in Southern sea otters (Enhydra lutris nereis) from 1998-2001. J. Wildl. Dis. 2003, 39, 495-509. [CrossRef] [PubMed]

29. Johannessen, J.N. Stability of domoic acid in saline dosing solutions. J. AOAC Int. 2000, 83, 411-412. [CrossRef]

30. Bates, S.; Wells, M.L.; Hardy, K. Photodegradation of domoic acid. Can. Tech. Rep. Fish. Aquat. Sci. 2003, 2498, 30-35.

31. Bouillon, R.-C.; Knierim, T.L.; Kieber, R.J.; Skrabal, S.A.; Wright, J.L.C. Photodegradation of the algal toxin domoic acid in natural water matrices. Limnol. Oceanogr. 2006, 51, 321-330. [CrossRef]

32. Mok, J.; Lee, T.-S.; Oh, E.-G.; Son, K.-T.; Hwang, H.-J.; Kim, J.H. Stability of domoic acid at different temperature, pH and light. Korean J. Fish. Aquat. Sci. 2009, 42, 8-14. [CrossRef]

33. Quilliam, M.A. Chemical methods for domoic acid, the amnesic shellfish poisoning (ASP) toxin. In Manual on Harmful Marine Microalgae; Hallegraeff, G.M., Anderson, D.M., Cembella, A.D., Eds.; Monographs on Oceanographic Methodology; Intergovernmental Oceanographic Commission (UNESCO): Paris, France, 2003; Volume 11, pp. 247-266.

34. McCarron, P.; Hess, P. Tissue distribution and effects of heat treatments on the content of domoic acid in blue mussels, Mytilus edulis. Toxicon 2006, 47, 473-479. [CrossRef]

35. Smith, E.A.; Papapanagiotou, E.P.; Brown, N.A.; Stobo, L.A.; Gallacher, S.; Shanks, A.M. Effect of storage on amnesic shellfish poisoning (ASP) toxins in king scallops (Pecten maximus). Harmful Algae 2006, 5, 9-19. [CrossRef]

36. Quilliam, M.; Xie, M.; Hardstaff, W. Rapid extraction and cleanup for liquid chromatographic determination of domoic acid in unsalted seafood. J. AOAC Int. 1995, 78, 543-554. [CrossRef]

37. Vale, P.; Sampayo, M. Evaluation of extraction methods for analysis of domoic acid in naturally contaminated shellfish from Portugal. Harmful Algae 2002, 1, 127-135. [CrossRef]

38. Frame, E.; Lefebvre, K. ELISA Methods for Domoic Acid Quantification in Multiple Marine Mammal Species and Sample Matrices; NOAA Technical Memorandum NMFS-NWFSC-122; U.S. Department of Commerce: Washington, DC, USA, 2013.

39. Ghasemi, A.; Zahediasl, S. Normality tests for statistical analysis: A guide for non-statisticians. Int. J. Endocrinol. Metab. 2012, 10, 486-489. [CrossRef] [PubMed]

40. Öztuna, D.; Elhan, A.H.; Tüccar, E. Investigation of four different normality tests in terms of type 1 error rate and power under different distributions. Turk. J. Med. Sci. 2006, 36, 171-176.

41. Rochon, J.; Gondan, M.; Kieser, M. To test or not to test: Preliminary assessment of normality when comparing two independent samples. BMC Med. Res. Methodol. 2012, 12, 81. [CrossRef] 